Volume 10, Issue 2, March-April 2019, pp.127-134, Article ID: IJM_10_02_012

Available online at http://iaeme.com/Home/issue/IJM?Volume $=10 \&$ Issue $=2$

Journal Impact Factor (2019): 9.6780 (Calculated by GISI) www.jifactor.com

ISSN Print: 0976-6502 and ISSN Online: 0976-6510

C IAEME Publication

\title{
MANAGEMENT OF INNOVATIVE ACTIVITY OF THE RUSSIAN ORGANIZATIONS ON THE BASIS OF SCENARIO APPROACH
}

\author{
Dr. Julia V. Fedorova \\ Doctor of Economics Sciences, Professor, I.M. Sechenov First Moscow State Medical \\ University (Sechenov University), Russia, Moscow
}

Dr. Dmitry S. Roshchin

Epidemiologist

AO «European Medical Center» Russia, Moscow

Dr. Natalia L. Borscheva

Associate Professor, I.M. Sechenov First Moscow State Medical University

(Sechenov University), Russia, Moscow

Dr. Marina I. Glukhova

Associate Professor, I.M. Sechenov First Moscow State Medical University

(Sechenov University), Russia, Moscow

\begin{abstract}
The article proposes a new methodological approach to assess the impact of external factors on the innovative activity of Russian organizations. The identification of such factors is necessary to improve the management of innovative organizations in Russia. The authors assess the factors of the external environment of innovative organizations. The correlation model is constructed and the key factors influencing innovative activity of the Russian organizations are revealed. A regression model reflecting the dependence of the level of innovative activity of organizations on changes in the external environment in the dynamics from 2005 to 2016 is constructed. Four variants of the scenario of changes in the number of innovative organizations in the Russian economy under the influence of external factors are constructed.
\end{abstract}

Key words: innovative organization, innovative activity, innovative development, management, external environment factors.

Cite this Article: Dr. Julia V. Fedorova, Dr. Dmitry S. Roshchin, Dr. Natalia L. Borscheva and Dr. Marina I. Glukhova, Management of Innovative Activity of the Russian Organizations on The Basis Of Scenario Approach, International Journal of Management, 10 (2), 2019, pp. 127-134.

$\mathrm{http} / / /$ iaeme.com/Home/issue/IJM?Volume $=10 \&$ Issue $=2$ 


\section{INTRODUCTION}

Today in Russia there is a low innovative activity of enterprises and organizations. The diagram (figure 1) shows the indicators of innovative activity of Russian companies in dynamics (Innovation statistics, 2017).

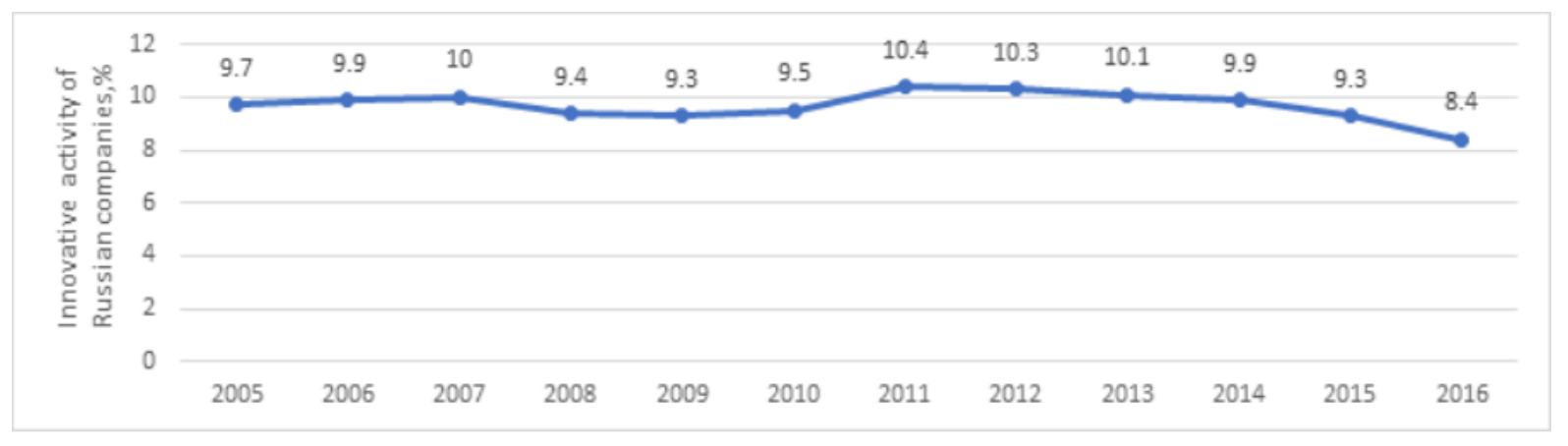

Figure.1 Innovative activity of Russian companies in dynamics from 2005 to 2016

To increase innovation activity and susceptibility to innovation of Russian organizations, the authors of this study propose to assess the impact of external conditions, to determine the factors that have the greatest and least impact on innovative organizations.

The external environment provides opportunities for any company to organize its successful activities, as well as the necessary resources to maintain the company's potential. The management of the enterprise needs to control the relationship with external factors, as the company is in close interaction with the external environment, both in the production process and in the process of implementation. There are four main characteristics of the external environment.

First, it is a difficulty. The complexity is due to the number of factors affecting the company. Complexity is an element that characterizes the number of environmental factors and the relationship between these factors. The external environment in terms of complexity can be classified as: homogeneous (simple environment) in which there is not a large number (3-4) similar elements of the external environment affecting the organization, and heterogeneous (complex environment), which contains many heterogeneous elements of the external environment of the company, affecting the organization, and are in close interaction with the company.

A homogeneous environment is more predictable for the Manager, which simplifies the process of development and management decision-making. The multiplicity and uniqueness of the factors influencing the activities of the organization is the number of significant objects, as well as their close connection with the activities of the organization.

The difficulty lies in the fact that the company must deal with a wide range of factors, the close connection with the activities of which is not always certain but is of great importance.

Secondly, it is the interconnectedness. The content of the element of interconnectedness is that the impact of some factors has an impact on the changes of others, and there is a degree of these changes. Interconnectedness of factors is the basic characteristic that determines the relationship between the company's activities and the impact of the external environment. Dependence or independence shows the density of the relationship of the company's activities with the external environment.

Isolation is also an indicator of the relationship between structures in the external environment. An isolated environment is peculiar by an unstable structure of communication with the subjects, or their absolute absence. 
The company in its activities, as a rule, is always in interaction with customers, partners, suppliers, consumers, competitors. At the same time, any company in its activities strives for maximum independence.

Third, uncertainty. The essence of the uncertainty element is the degree of ownership of information about changes in the environment, as well as the degree of confidence in the reliability and accuracy of the information received.

A situation in which the company does not have sufficient information on the status and trends of external factors of Seda increases the risk of unsatisfactory performance of the company as a whole.

Fourth, variability. By its nature, the element of variability is to determine the mobility of environmental factors.

For the successful functioning of any company, the most important thing is the stability of relations with the external environment. In situations where there is a high level of complexity and mobility of the environment, then to solve these problems, management needs to rely on information obtained from different sources, as well as be able to change their own priorities. In some cases, to make successful decisions, it is important to be able to revise the formed system of values and culture of the company.

In the context of dynamic changes in environmental factors, it is necessary to carry out regular monitoring and analysis of new strategies and approaches. This knowledge will allow to make adequate and balanced decisions.

It should be marked that today there is no single established classification of factors affecting the innovation of staff. Today, there are several opinions about what factors have an impact on work motivation.

Several specialists classify factors only based on classification based on belonging to external and internal, direct and indirect. Factors with indirect effects are more complex than those with direct effects. For our research, indirect impact factors are of greater scientific interest.

Factors of indirect influence of the external environment are classified into five groups, while external factors experts include: political and legal (changes in the regulatory framework and the political situation in the country), economic (General state of the economy, the state of the labor market, capital, changes in working conditions), technological (changes in technological standards, the development of technologies in the field of production and business processes), social (social standards, ethnic norms, social values, social and psychological factors), international (international migration, etc.).

The analysis of external factors needs conduct on an ongoing basis, as it accumulates information that allows an assessment of the current situation.

Analysis of the external environment is the process by which the developers of strategic innovation direction in the company keep under control external to the organization moments to qualify threats and opportunities. The analysis of the external environment contains:

- Economic impact study,

- Study of the impact of legal regulation and management,

- Study of political processes,

- Study of the natural environment and resources,

- Research of social and cultural component of society,

- Research of scientific and technological development of society, infrastructure, etc. 
Qualitative analysis of the external environment can help to obtain meaningful results. Eventually of timely carrying out of such analysis the organization receives:

- Time to predict probabilities,

- Time to draw up an intention in case of unexpected events,

- Time to develop an early warning system for probable hazards,

- Time to develop strategies that have all the chances to turn the former dangers into all sorts of profitable opportunities.

\section{MATERIALS AND METHODS}

To determine the key factors influencing the development of innovative organizations in the Russian economy, economic and statistical methods were used, in particular, correlation and regression analysis was applied. Its task was to assess the degree of influence of environmental factors on the number of innovative organizations in the Russian economy. In the course of this study, political, economic, socio-demographic, technological, international factors affecting the innovative activity of organizations (92 macro factors) were analyzed (Hochberg L., 2018; Gorodnikova N., Hochberg L., 2018; Gorodnikova N, Gokhberg L., Ditkovskiy K, 2018 ). As a result, the indicator "Number of innovative organizations" was chosen.

When performing the analysis, some methodological assumptions were made that are significant from the standpoint of the interpretation of the results. Thus, the correlation and regression analysis was performed at unbiased levels due to the short time series and the need for empirical confirmation of the hypothesis of the relationship between the factors and the resulting indicator for further research.

The selection of macro factors is performed according to the criterion of the greatest pair correlation between them and the resulting indicator. The constructed correlation model revealed a close connection of the resulting indicator with such factors as "Developed advanced production technologies" $(\mathrm{r}=0.92)$, "participation of organizations in joint international innovation projects for research and development" ( $\mathrm{r}=0.93)$, "New Russian technologies (technical achievements) transferred to foreign and Russian organizations engaged in technological innovations" $(\mathrm{r}=0.98)$. Statistical data for the regression model is presented in table 1 (Hochberg, L., 2018).

Tabel 1 Statistical data for creation of regression model

\begin{tabular}{|c|c|c|c|c|}
\hline & $\begin{array}{c}\text { Innovative } \\
\text { organizations, } \\
\text { thousands of } \\
\text { units } \\
(\mathrm{y})\end{array}$ & $\begin{array}{c}\text { Developed } \\
\text { advanced } \\
\text { production } \\
\text { technologies, } \\
\text { units } \\
(\mathrm{x} 1)\end{array}$ & $\begin{array}{c}\text { Participation of } \\
\text { organizations in joint } \\
\text { international innovation } \\
\text { projects for research and } \\
\text { development, unit projects } \\
(\mathrm{x} 2)\end{array}$ & $\begin{array}{c}\text { New Russian technologies } \\
\text { (technical achievements) } \\
\text { transferred to the Russian } \\
\text { and foreign organizations } \\
\text { which carried out } \\
\text { technological innovations, } \\
\text { units (x3) }\end{array}$ \\
\hline 2005 & 456 & 637 & 634 & 970 \\
\hline 2006 & 456 & 736 & 705 & 991 \\
\hline 2007 & 451 & 780 & 750 & 671 \\
\hline 2008 & 448 & 787 & 811 & 830 \\
\hline 2009 & 456 & 789 & 838 & 539 \\
\hline 2010 & 458 & 864 & 886 & 548 \\
\hline 2011 & 502 & 1138 & 1345 & 5628 \\
\hline 2012 & 496 & 1323 & 1315 & 6282 \\
\hline 2013 & 500 & 1429 & 1529 & \\
\hline
\end{tabular}



Approach

\begin{tabular}{|c|c|c|c|c|}
\hline 2014 & 483 & 1409 & 1521 & 4011 \\
\hline 2015 & 499 & 1398 & 1771 & 6408 \\
\hline 2016 & 511 & 1534 & 1685 & 5955 \\
\hline \multicolumn{2}{|l|}{ Correlation coefficient } & $\mathbf{0 . 9 2}$ & $\mathbf{0 . 9 3}$ & $\mathbf{0 . 9 8}$ \\
\hline
\end{tabular}

To confirm the influence of the identified key factors (positive influence of factors $\mathrm{x} 1, \mathrm{x} 2$, $\mathrm{x} 3$ ) on the resulting indicator, a regression model was built. Analysis of the factors in the macro environment influencing the innovative activity of Russian enterprises and organizations in the obtained regression model allowed to identify the trends of key factors in the macro environment and to build a real model in the form of the formula:

$\mathrm{y}=443,599+0,00784 \times 1-0,0027 \times 2+0,008562 \times 3$

$x 1$ - developed advanced production technologies, units

$x 2$ - participation of organizations in joint international innovation projects for research and development, unit projects

$x 3$ - new Russian technologies (technical achievements) transferred to the Russian and foreign organizations which carried out technological innovations, units

In the constructed real (regression) model, the resulting indicator is positively influenced by the factors "Developed advanced production technologies " (x1) and" New Russian technologies (technical achievements) transferred to foreign organizations "(x3), and the factor "Participation of industry organizations in joint international innovative projects for research and development" (x2).

The negative impact of the factor $(\mathrm{x} 2)$ can be explained by the fact that the number of joint international innovative research projects involving industrial organizations is constantly increasing, but the results are not always implemented in Russian organizations. The negative impact of the second factor can be explained by the lack of effectiveness of joint research projects.

The strategic development of innovative organizations is largely associated with changes in the external environment and is determined by the scenario of changes in the external environment. The study analyzed four possible scenarios: realistic (based on trends), conservative, innovative, forced. The forecast values of the factors influencing the innovative activity of enterprises and organizations in a realistic scenario were obtained by constructing trend lines (linear, logarithmic, and polynomial). The coefficient of approximation $\left(\mathrm{R}^{2}\right)$ was used as a selection criterion results in the construction of trend lines in different ways.

The approximation coefficient $\left(\mathrm{R}^{2}\right)$ became the criterion for selecting the result. For the factor, $\mathrm{x} 1, \mathrm{x} 2, \mathrm{x} 3$, the trend lines are constructed in a polynomial way, since they have a higher value of the approximation coefficient compared to the logarithmic and linear way (fig.2, fig.3, fig.4). 
Dr. Julia V. Fedorova, Dr. Dmitry S. Roshchin, Dr. Natalia L. Borscheva and Dr. Marina I. Glukhova

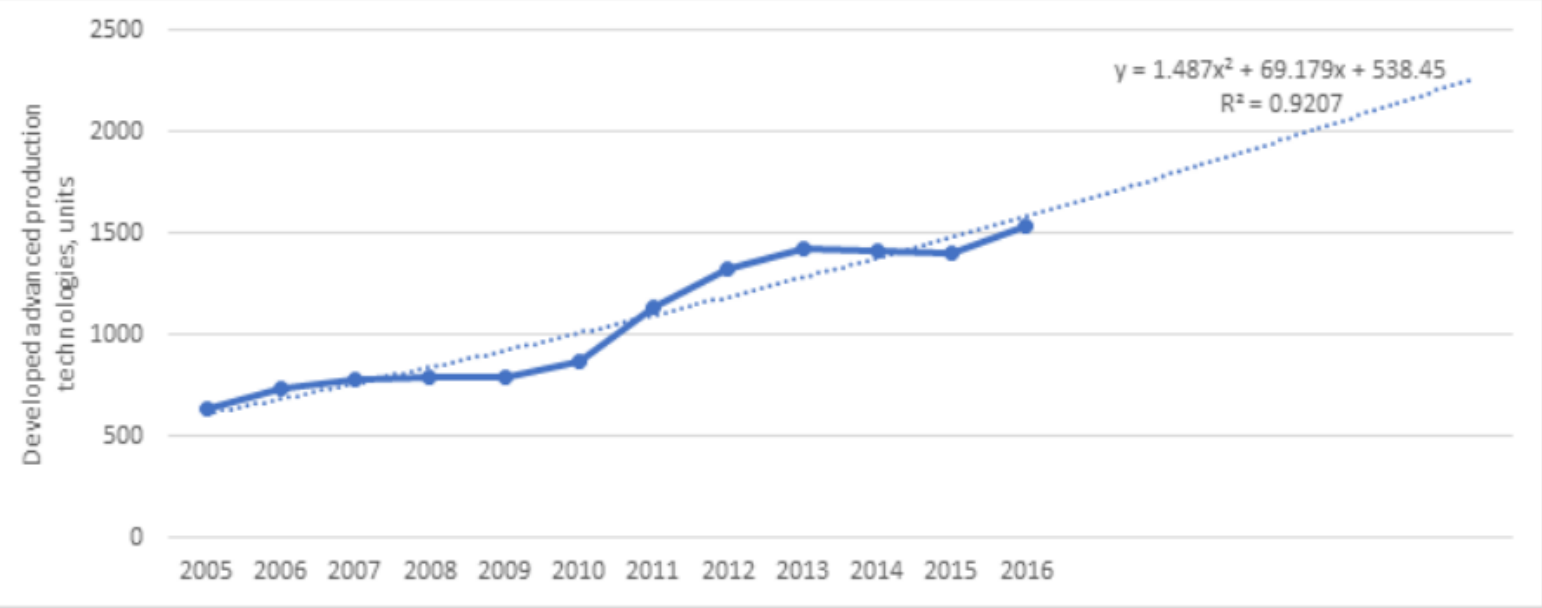

Figure.2 Polynomial trend line for the factor "Developed advanced production technologies»

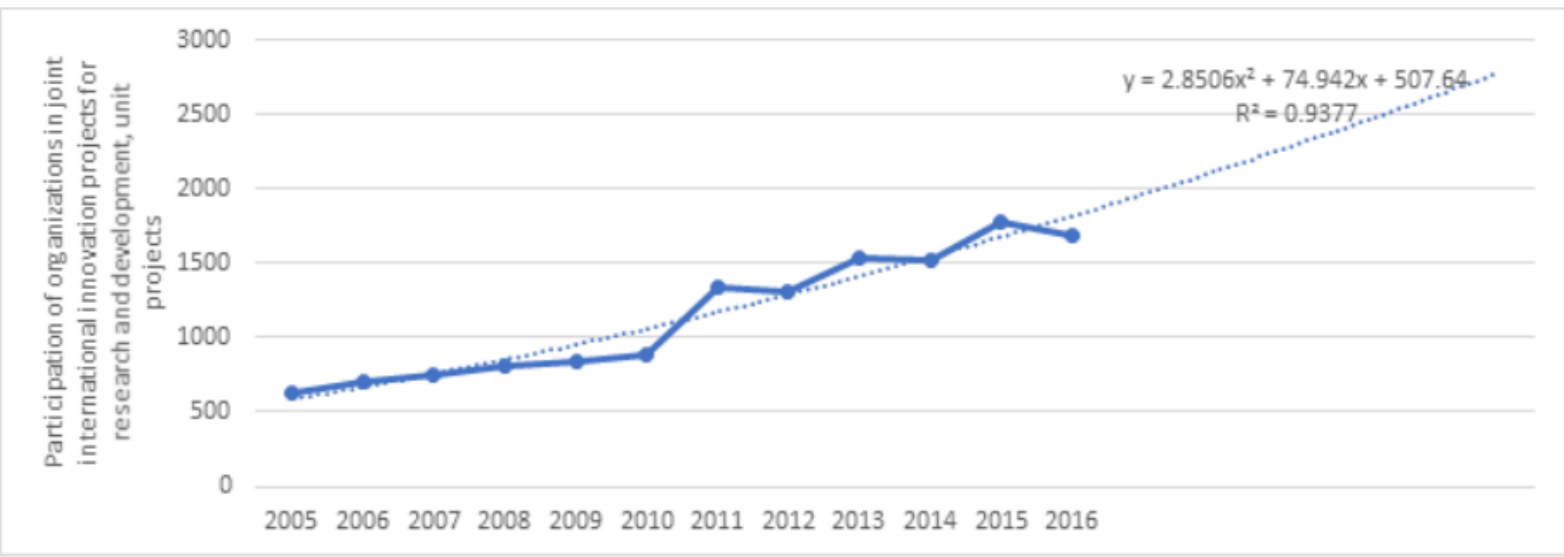

Figure.3 Polynomial trend line for the factor « Participation of organizations in joint international innovation projects for research and development»

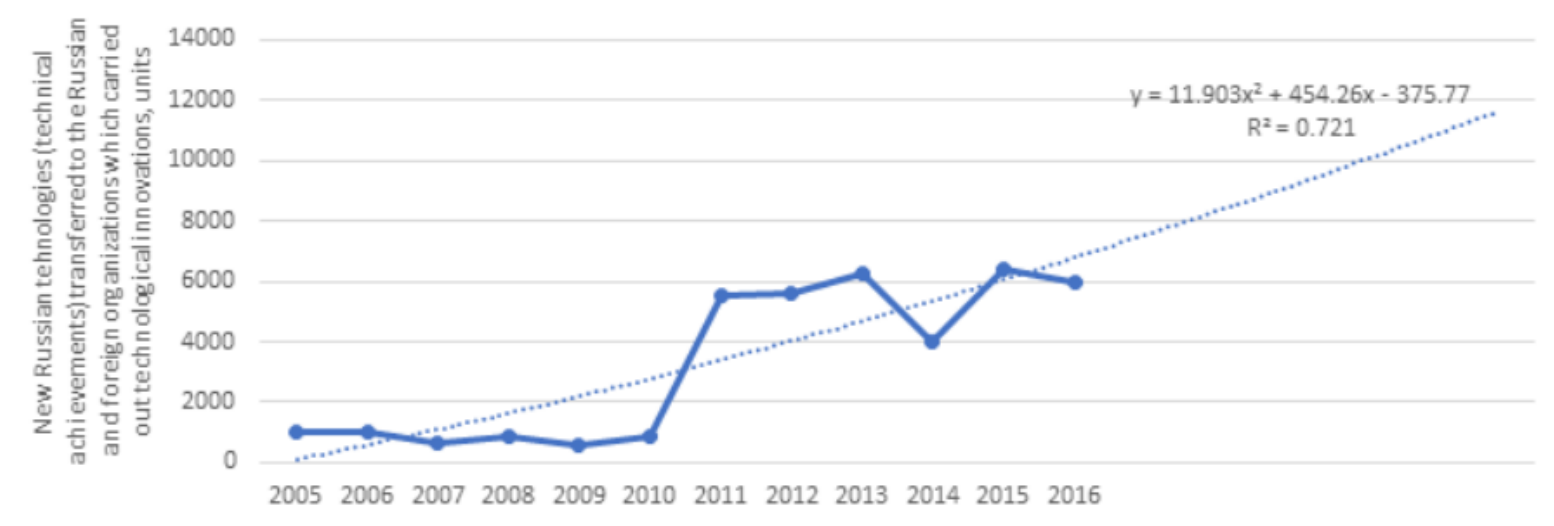

Figure.4 Polynomial trend line for the factor «New Russian technologies (technical achievements) transferred to the Russian and foreign organizations which carried out technological innovations»

\section{RESULTS \& DISCUSSION}

The results of calculations of predictive values of factors obtained by constructing trend lines are presented in fig. 5 . 


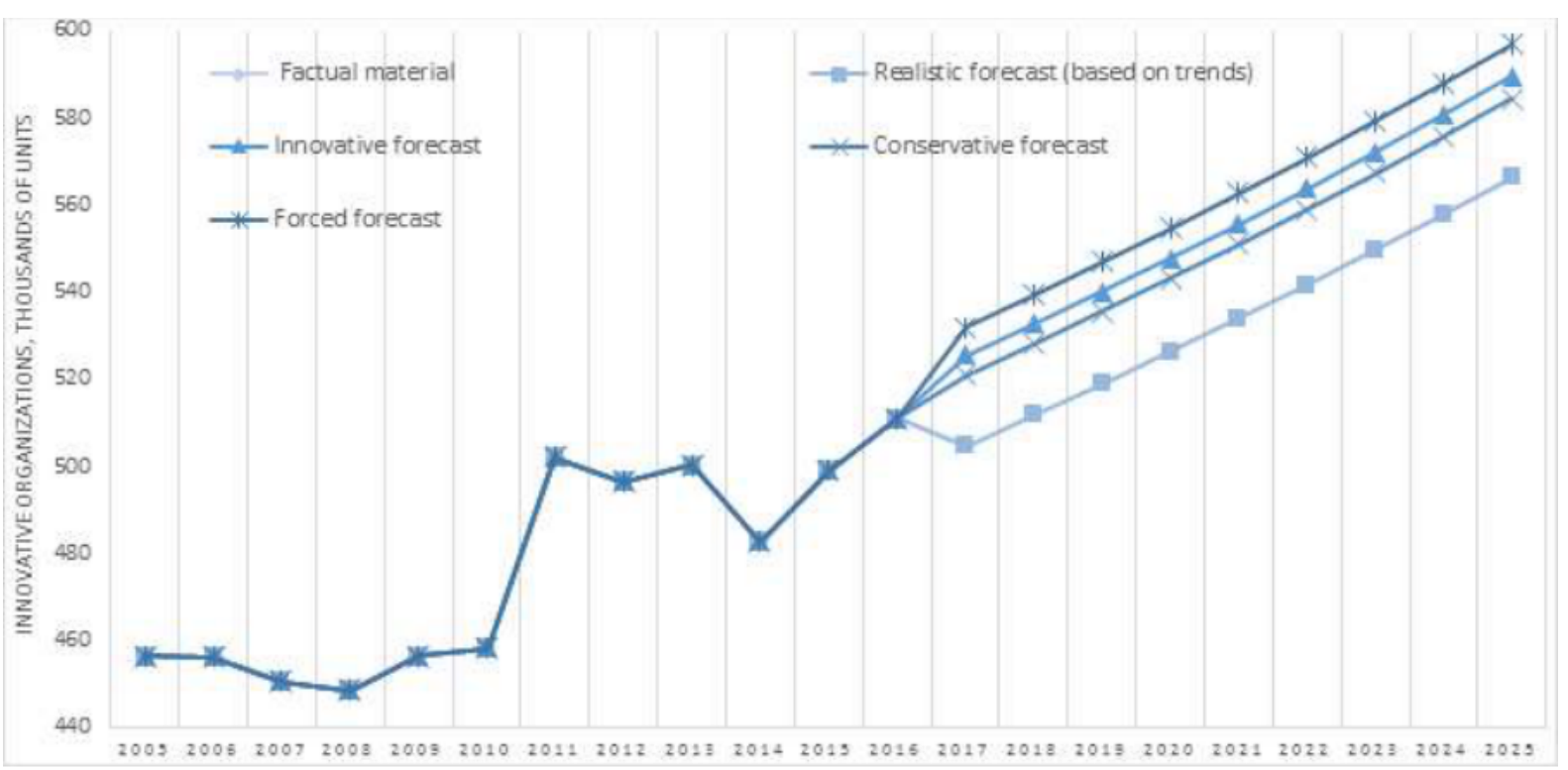

Figure. 5 Scenarios of changes in the number of innovative organizations under the influence of relevant macro factors

Data from the Ministry of economic development of the Russian Federation were used to calculate conservative, innovative and forced scenarios. The obtained predictive values of the key factors of the microenvironment influencing the innovative activity of Russian organizations were used to calculate the number of innovative organizations in the Russian economy by substituting them (values of factors) in the real (regression) model (1). In a realistic scenario, the number of innovative organizations in 2025 amounted to 566327 units. in a conservative scenario 584449 units., in an innovative scenario 589546 units., in a forced scenario 596909 units.

\section{CONCLUSIONS}

Thus, the paper tested the tools of the initial assessment of environmental factors affecting the innovative activity of Russian organizations. The actual external factors influencing changes in the number of innovative organizations in the Russian economy are revealed. Realistic, conservative, innovative and forced forecasts of changes in the number of innovative organizations up to 2025 taking into account the influence of the identified relevant strategic factors are built.

In the study, we can conclude that if the trend of the key factors in the macro will not change significantly, the number of innovative organizations in 2025 will amount to 566327 units. In the conservative scenario the number of innovative organizations in 2025 will increase to 584 449. Innovation in the forecast is expected to increase to 589546 innovative organizations. When the forced scenario also projected to increase to 596909 units of the organizations innovative activity.

Identified and confirmed at this stage of the study the relationship between the macro factors affecting the innovation activity of organizations opens up a significant number of reasons for discussion and further in-depth study of the problem in order to develop sound recommendations for changing or clarifying the state innovation policy. 
Dr. Julia V. Fedorova, Dr. Dmitry S. Roshchin, Dr. Natalia L. Borscheva and Dr. Marina I. Glukhova

\section{REFERENCES}

[1] Innovation statistics, Electronic resource: http:// gtmarket.ru, 2017

[2] Valentina Ivashova, Vadim Goncharov, Alexey Erokhin, Olga Kolosova and Vyacheslav Berkovsky, Life Strategies of Graduates of Regional Universities: the Reality of Russian Society, International Journal of Civil Engineering and Technology, 9(13), 2018, pp. 398 404

[3] Hochberg, L. Indicators of innovation statistical yearbook Higher School of Economics, 2017

[4] Gorodnikova, N., Hochberg, L. Science indicators, statistical yearbook Higher School of Economics, 2018

[5] Bitopi Gogoi and Mukulesh Barua. Creative Orientation and Individual Innovativeness An Empirical Study. Journal of Management, 5(1), 2018, pp. 33-42.

[6] Indicators of Innovation in the Russian Federation, Data Book / N. Gorodnikova, L. Gokhberg, K. Ditkovskiy et al.; National Research University Higher School of Economics. - Moscow: HSE, 2018.

[7] Vladimir A. Grachev, Environmental Safety of Nuclear Power Plants of Russian Design, International Journal of Mechanical Engineering and Technology, 9(11), 2018, pp. 172176.

[8] Elena Irekovna Beglova, Svetlana Irekovna Nasyrova and Azat Vazirovich Yangirov, Assessment of Migration Attractiveness of Russian Federation Federal Districts, International Journal of Civil Engineering and Technology (IJCIET) 9(12), 2018, pp. 323338.

[9] Dr. A. Ramaraju, a Role of Innovative Idea Management in Hrm, International Journal of Management (IJM), Volume 5, Issue 8, August (2014), pp. 25-34

[10] Alexandr L. Elyakov,Izabella D. Elyakova,Alexandr A. Pakhomov and Vasiliy R. Darbasov, Economic And Legal Mechanism for The Development of Renewable Energy Sources in The Arctic Zone of The Russian Federation. International Journal of Civil Engineering and Technology, 10(10), 2018, pp. (1072)- (1083).

[11] Tatiana Viktorovna Krupa, Management of Innovative Developments of Educational Institutions in World and Russian Practice, International Journal of Mechanical Engineering and Technology, 10(01), 2019, pp.1251-1262 